\title{
Reconstruction Of Maxillofacial Defects: A Retrospective Institutional Study
}

Research Article

\author{
R Rajashri ${ }^{1}$, M P Santhosh Kumar ${ }^{2 *}$, Kathiravan Selvarasu ${ }^{3}$
}

${ }^{1}$ Department of Oral and Maxillofacial Surgery, Saveetha Dental College and Hospitals, Saveetha Institute of Medical and Technical Sciences, Saveetha University, Chennai, India.

${ }^{2}$ Reader, Department of Oral and Maxillofacial Surgery, Saveetha Dental College and Hospitals, Saveetha Institute of Medical and Technical Sciences, Saveetha University, Chennai, India.

${ }^{3}$ Senior Lecturer, Department of Oral and Maxillofacial Surgery, Dental College and Hospitals, Saveetha Dental College and Hospitals, Saveetha Institute of Medical and Technical Sciences, Saveetha University, Chennai, India.

\section{Abstract}

This study aims to evaluate the maxillofacial defects and the types of flaps employed to reconstruct the lost framework of head and neck among patients treated in our institution. This hospital-based retrospective study was done at the Department of Oral and Maxillofacial Surgery, Saveetha Dental College, Chennai, Tamil Nadu, from the case record of patients who underwent resection followed by reconstruction for various pathologies from July 2019 to March 2020. Consecutive case records of all the patients who had reconstructive surgeries for maxillofacial defects were included in the study. Various parameters of the patients were retrieved from the patient digital data registry and recorded. All patients underwent surgeries for defects in the maxillofacial region followed by reconstruction. Descriptive statistics and a regression model were used to assess the relationship between the site of defect and the type of flap used. Pearson's chi square test was done to test the association between categorical variables. The study was analysed using the IBM Statistical Package for the Social Sciences (SPSS) Statistics, version 20.0 and results obtained. A total of 47 patients aged more than 6 years were studied, with the average age being $51.68+/-13.4$ years. In our study out of 47 patients, 11 were female and 36 were male. Majority of patients who underwent surgery belonged to 41-60 years of age followed by $61-70$ years of age. $89.4 \%$ of patients underwent surgery for oral Squamous cell carcinoma which included both males and females. A statistically significant association between the type of defect encountered and the reconstructive technique employed was present. Chi square test; $\mathrm{p}<0.001$. Within the limits of this study, the predominant pathology for which resection is carried out among patients is oral squamous cell carcinoma which is seen mostly in the middle aged group. Males were mostly affected by pathology than females. Reconstructive surgery with flaps is the most common type of management. Free fibula flap was 9.31 times more likely to be employed for defects in the mandible. With an increase in complexity and size of the maxillofacial defect, the type of reconstructive surgery also varies.

Keywords: Maxillofacial Defects; Reconstructive Surgery; Oral Squamous Cell Carcinoma; Oral Submucous Fibrosis; Free Flap; Fibula Flap.

\section{Introduction}

The human body acquires facial defects as a result of diverse types of insults. They include trauma from road traffic accidents or surgical resection of diseased tissue due to neoplasms, infection, and necrosis involving defects of both hard and soft tissue. [1-4]. Not only are they challenging to reconstruct but they also require surgical skill and sound knowledge in anatomy $[5,6]$.
Head and neck cancer is a big global health issue which is definitively managed by complete microscopic surgical excision followed by reconstruction [7-10]. Thus, choosing the right reconstruction technique is crucial while treating these patients [11] [12]. Operative techniques and perioperative management have also greatly improved the overall success of the surgical procedure $[13,14]$.

There is no one panacea reconstructive option for every defect

*Corresponding Author:

M P Santhosh Kumar,

Reader, Department of Oral and Maxillofacial Surgery, Saveetha Dental College and Hospitals, Saveetha Institute of Medical and Technical Sciences, Saveetha University, Chennai, India.

E-mail: santhoshkumar@saveetha.com

Received: October 07, 2020

Accepted: November 22, 2020

Published: November 25, 2020

Citation: R Rajashri, M P Santhosh Kumar, Kathiravan Selvarasu. Reconstruction Of Maxillofacial Defects: A Retrospective Institutional Study. Int J Dentistry Oral Sci. 2020; 7(11):10901093. doi: http://dx.doi.org/10.19070/2377-8075-20000216

Copyright: M P Santhosh Kumar ${ }^{\circ} 2020$. This is an open-access article distributed under the terms of the Creative Commons Attribution License, which permits unrestricted use, distribution and reproduction in any medium, provided the original author and source are credited. 
and each technique has advantages and disadvantages [15-18]. In some cases, a vascularized free flap is the ideal choice while in some cases, local flaps can provide equivalent, or superior, functional and esthetic results [19]. Multiple algorithms have been showcased to address the various defects and their reconstruction $[20,21]$.

This study aims to evaluate the maxillofacial defects and the types of flaps employed to reconstruct the lost framework of head and neck among patients treated in our institution.

\section{Materials and Methods}

\section{Study design and study setting}

We conducted a hospital-based retrospective case-control study at Saveetha Dental College, Department of Oral and Maxillofacial Surgery, Chennai, Tamil Nadu, from July 2019 to March 2020. The study was initiated after approval from the institutional review board. (SDC/SIHEC/2020/DIASDATA/0619-0320).

\section{Patient Population and Data Collection}

This is a retrospective study based on analysis of patient records. All the patients who had reconstructive surgeries of maxillofacial defects were included in the study. Patients with missing or incomplete data, and patients managed by adjuvant non surgical therapies were excluded from the study. The study design was observational (cross-sectional survey). The parameters that were studied included:

- Age

- Gender

- Site of Maxillofacial Defect

- Etiology

- Type of surgical correction: reconstructive surgery using flap or primary closure or use of other materials to achieve closure.

- Type of Flaps used

In our study, 42 patients were diagnosed with oral squamous cell carcinoma, 2 patients with oral submucous fibrosis, 1 patient with ameloblastoma, 1 patient with congenital deformity and 1 patient with post traumatic deformity. The treatment plan for all the patients was discussed with a multidisciplinary team. The maxillofacial defects were classified based on a new classification system which classified the composite defects according to two factors: the elements and distribution of the missing tissues which led to 4 types as follows:

Type A: Only elements of soft tissue missed in a close one-block pattern.

Type B: Only elements of soft tissue missed but in a wide separate-block pattern.

Type C: Both elements of soft tissue and bone missed in a close one-block pattern.

Type D: Both elements of soft tissue and bone missed but in a wide separate-block pattern.

This classification helps in understanding the features of the defects and for selection of a specific reconstructive technique [22]. The type of reconstructive surgery was categorized based on the type of closure with/without the use of flap or synthetic materials.

\section{Statistical analysis}

Descriptive statistics and a regression model were used to assess the relationship between the site of defect and the type of flap used. Pearson's chi square test was done to test the association between categorical variables. The exposure variables include age, gender, etiology, mode of surgical correction, site of defect and type of flaps. The dependent variable was the reconstructive technique. Covariates were controlled to increase the validity of the study. Odds ratio (OR) and 95\% confidence interval (CI) were used to assess the type of defect sustained and the type of flap employed. The type of flaps chosen were further analysed by using ordinal logistic regression. Logistic regression analysis was utilized to control the confounding variables. The study was analysed using the IBM Statistical Package for the Social Sciences (SPSS) Statistics, version 20.0 and results obtained.

\section{Results and Discussion}

Of the total 47 patients recruited into the study, 11 were female and 36 were male. Patients were grouped based on their age. One was within childhood age (0-9 years), five were within young adulthood (20-40 years), twenty eight were within middle age (40-60 years), and thirteen were within elderly age (60 years and above) Majority of patients who underwent surgery belonged to 41-60 years of age followed by 61-70 years of age with male predilection. (Figure 1).

Pathologically, 89.4\% had Squamous cell carcinoma with 17 patients presenting in gingivobuccal sulcus, 10 patients in tongue, 10 patients in both maxilla \& mandible, 1 patient in the hard palate and 4 patients in buccal mucosa. $4.3 \%$ patients presented with dysplasia associated with oral submucous fibrosis and $2.1 \%$ patients affected by ameloblastoma, post traumatic and congenital deformities each. Oral squamous cell carcinoma is the main cause for the surgery both in males and females with males showing a slightly higher predilection. (Figure 2).

Of the total 47 patients, 13 (4 female, 9 male) patients had no reconstruction with flap, while 34 ( 9 female, 25 male) patients had reconstruction with flap. The flaps employed were Pectoralis major myocutaneous flap $(n=10)$, followed by Free fibula flap $(n=7)$, Radial forearm flap $(n=5)$, Loco regional rotational flap $(n=3)$, split skin graft $(n=3)$ and medial sural microvascular flap $(n=1)$. Two patients underwent repeated surgeries due to flap failure at different intervals during follow up. One patient achieved closure with the help of collagen membrane. The remaining patients underwent primary closure. All the patients were followed up and there was no morbidity or mortality. Association between type of reconstructive surgery and type of maxillofacial defect was evaluated. Chi-Square test was done and the results were statistically significant. p value: $0.001(<0.05)$ Hence proving presence of a statistically significant association between the type of defect encountered and the reconstructive technique employed. (Figure 3). However, a logistic regression analysis showed that mandibular defects were 9.31 times more likely to undergo reconstruction with flap than the defects of maxilla and other regions. The odds for the need for reconstructive surgery with flaps were not signifi- 
Figure 1. Bar chart depicting the gender wise distribution of patients in age categories. $X$ axis denotes age of the patients in categories and $\mathrm{Y}$ axis denotes number of patients who underwent surgery gender wise. Majority of patients who underwent surgery belonged to 41-60 years of age followed by 61-70 years of age with male predilection.

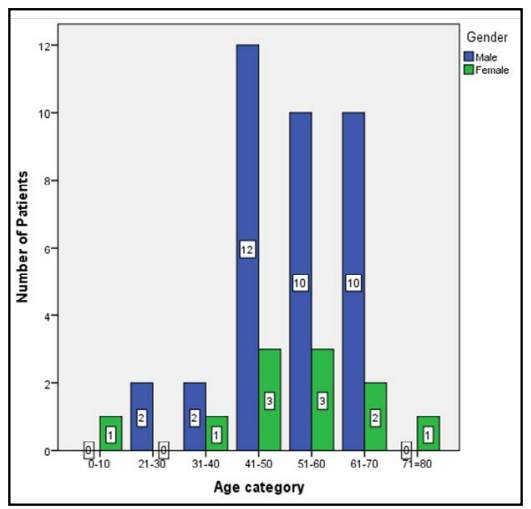

Figure 2. Bar chart depicting gender wise distribution of etiology for surgery in patients. $\mathrm{X}$ axis denotes etiology for surgery and $\mathrm{Y}$ axis denotes the number of patients who underwent surgery gender wise. Oral squamous cell carcinoma is the main cause for the surgery both in males and females with males showing a slightly higher predilection.

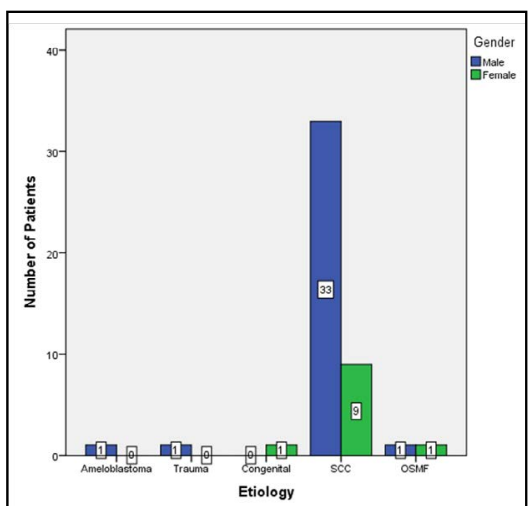

Figure 3. Bar chart depicting association between type of reconstructive surgery and type of maxillofacial defect. $\mathrm{X}$ axis denotes type of reconstructive surgeries performed for patients and $Y$ axis denotes number of patients with various maxillofacial defects defect type wise. Chi-Square test was done and the results were statistically significant. Pearsons's Chi Square value: 36.72 , DF:14, p value: $0.001(<0.05)$ Hence proving presence of a statistically significant association between the type of defect encountered and the reconstructive technique employed.

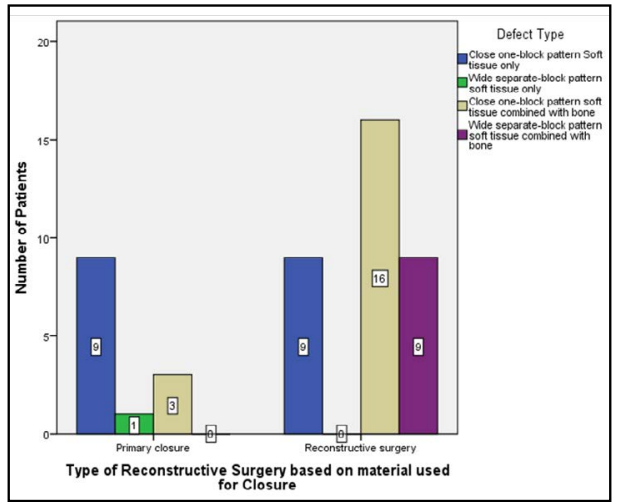

cant with respect to other defect types.

In our study, the age range of the patients was 6 to 71 years, and the mean age was $51.68+/-13.49$ years. The shortest hospital length of stay was one day, while the longest was 20 days. Overall, there is no relationship between age, gender and type of defect with the type of surgery performed. The descriptive statistics showed that most of our study population were in the middleage group and predominantly of male gender. Males represented the majority across multiple studies observed [23-25]. According to our study, Mandibular defects were 9.31 times more likely to undergo reconstruction with flap than the defects of maxilla and other regions. Unfortunately, the sample size for this study is small, which is a limitation of this study design. If a larger sample size were used, there might have been some significant differences between the type of defects and mode of reconstructive surgery. Also, unequal gender distribution may be responsible for the mild gender differences in the type of reconstructive surgery.

A plethora of flaps are available in the maxillofacial region that can be used to reconstruct defects caused by maxillofacial trauma, burns, carcinoma, congenital defects, pathologies like cysts etc [6]. Cancer ablative surgeries account for the majority of the defects according to this study. Reconstruction of these maxillofacial de- 
fects depends on the timing of diagnosis and status of the existing structures along with the size and location of the defect [26]. Clinical evaluation of composite oral and maxillofacial defects is an important step in the reconstruction of these defects [27]. Free flaps are the gold standard for reconstruction of the mandible, tongue and floor of the mouth. The most preferable option for reconstruction of complex mandibular defects, as well as for tongue and floor of the mouth is reconstruction with Free fibula flaps, due to ease of harvesting the flap, and as it presents excellent functional outcomes. The bone reconstruction includes the fibular and iliac crest free flap, and for soft tissue reconstruction includes the anterolateral thigh, the radial forearm free flap, and the nasolabial island flap [28]. The results of this study were in agreement with the previous available literature. It is evident from many studies that men of the middle-aged group commonly undergo reconstructive surgery for various pathologies of the oral cavity and jaw.

There is a paucity of literature regarding utilization of the classification and the type of reconstructive surgery employed. A larger sample size in future studies will be useful to propose a proper treatment plan for various maxillofacial defects.

\section{Conclusion}

Within the limits of this study, the predominant pathology for which resection is carried out among patients is oral squamous cell carcinoma which is seen mostly in the middle aged group. Males were mostly affected by pathology than females. Reconstructive surgery with flaps is the most common type of management. Free fibula flap was 9.31 times more likely to be employed for defects in the mandible. With an increase in complexity and size of the maxillofacial defect, the type of reconstructive surgery also varies.

\section{Acknowledgements}

This study was supported by Saveetha Dental College and Hospitals, Saveetha Institute of Medical and Technical Sciences, Chennai.

\section{References}

[1]. Kumar S. Relationship between dental anxiety and pain experience during dental extractions. Asian J Pharm Clin Res. 2017;10(3):458-61.

[2]. Packiri S, Gurunathan D, Selvarasu K. Management of paediatric oral ranula: a systematic review. J. Clin. Diagnostic Res. 2017 Sep;11(9):ZE06-9.

[3]. Patturaja K, Pradeep D. Awareness of Basic Dental Procedure among General Population. Res J Pharm Technol. 2016;9(9):1349-51.

[4]. Rao TD, Kumar MP. Analgesic Efficacy of Paracetamol Vs Ketorolac after Dental Extractions. Res J Pharm Technol. 2018;11(8):3375-9.

[5]. Mittal G, Agarwal A, Kataria G. Flaps for Oral and Maxillofacial Reconstruction: Review of Literature and a Clinical Guide to the Clinicians. Asian J Oncol. 2019 Jul;4(02):037-42.

[6]. Abhinav RP, Selvarasu K, Maheswari GU, Taltia AA. The Patterns and Etiology of Maxillofacial Trauma in South India. Ann Maxillofac Surg. 2019 Jan-Jun;9(1):114-117.Pubmed PMID: 31293938.

[7]. Bray F, Ferlay J, Soerjomataram I, Siegel RL, Torre LA, Jemal A. Global cancer statistics 2018: GLOBOCAN estimates of incidence and mortality worldwide for 36 cancers in 185 countries. CA: Cancer J Clin. 2018 Nov;68(6):394-424.

[8]. Marimuthu M, Andiappan M, Wahab A, Muthusekhar MR, Balakrishnan A, Shanmugam S. Canonical Wnt pathway gene expression and their clinical correlation in oral squamous cell carcinoma. Indian J Dent Res. 2018 MayJun;29(3):291-297.Pubmed PMID: 29900911.
[9]. Homer JJ, Fardy MJ. Surgery in head and neck cancer: United Kingdom national multidisciplinary guidelines. J Laryngol Otol . 2016 May;130(S2):S68-70.

[10]. Nayar S. Current concepts and novel techniques in the prosthodontic management of head and neck cancer patients. Br Dent J. 2019 May;226(10):725-737.Pubmed PMID: 31127217.

[11]. Palmieri M, Sarmento DJS, Falcão AP, Martins VAO, Brandão TB, MoraisFaria K, et al. Frequency and Evolution of Acute Oral Complications in Patients Undergoing Radiochemotherapy Treatment for Head and Neck Squamous Cell Carcinoma. Ear Nose Throat J. 2019 Oct 17:145561319879245. Pubmed PMID: 31619067.

[12]. Vijayakumar Jain S, Muthusekhar MR, Baig MF, Senthilnathan P, Loganathan S, Abdul Wahab PU, et al. Evaluation of Three-Dimensional Changes in Pharyngeal Airway Following Isolated Lefort One Osteotomy for the Correction of Vertical Maxillary Excess: A Prospective Study. J Maxillofac Oral Surg. 2019 Mar;18(1):139-146.Pubmed PMID: 30728705.

[13]. Jesudasan JS, Wahab PU, Sekhar MR. Effectiveness of $0.2 \%$ chlorhexidine gel and a eugenol-based paste on postoperative alveolar osteitis in patients having third molars extracted: a randomised controlled clinical trial. $\mathrm{Br} J$ Oral Maxillofac Surg. 2015 Nov;53(9):826-30.Pubmed PMID: 26188932.

[14]. Sweta VR, Abhinav RP, Ramesh A. Role of Virtual Reality in Pain Perception of Patients Following the Administration of Local Anesthesia. Ann Maxillofac Surg. 2019 Jan-Jun;9(1):110-113.Pubmed PMID: 31293937.

[15]. Kumar S. The emerging role of botulinum toxin in the treatment of orofacial disorders: literature update. Asian J Pharm Clin Res. 2017;10(9):21.

[16]. Kumar S, Rahman RE. Knowledge, awareness, and practices regarding biomedical waste management among undergraduate dental students. Asian J Pharm Clin Res. 2017;10:341.

[17]. Kumar S, Snena S. Knowledge and awareness regarding antibiotic prophylaxis for infective endocarditis among undergraduate dental students. Asian J Pharm Clin Res. 2016;9:154-9.

[18]. Kumar V, Patil K, Munoli K. Knowledge and attitude toward human immunodeficiency virus/acquired immuno deficiency syndrome among dental and medical undergraduate students. J Pharm Bioallied Sci. 2015 Aug;7(Suppl 2):S666-71.Pubmed PMID: 26538940.

[19]. Patil SB, Durairaj D, Suresh Kumar G, Karthikeyan D, Pradeep D. Comparison of Extended Nasolabial Flap Versus Buccal Fat Pad Graft in the Surgical Management of Oral Submucous Fibrosis: A Prospective Pilot Study. J Maxillofac Oral Surg. 2017 Sep;16(3):312-321.Pubmed PMID: 28717289.

[20]. George RK, Krishnamurthy A. Microsurgical free flaps: Controversies in maxillofacial reconstruction. Ann. Maxillofac. Surg. 2013 Jan;3(1):72-9.

[21]. Christabel A, Anantanarayanan P, Subash P, Soh CL, Ramanathan M, Muthusekhar MR, et al. Comparison of pterygomaxillary dysjunction with tuberosity separation in isolated Le Fort I osteotomies: a prospective, multi-centre, triple-blind, randomized controlled trial. Int J Oral Maxillofac Surg. 2016 Feb;45(2):180-5.Pubmed PMID: 26338075.

[22]. Yao XY, Liu H, Liu WW. Reconstruction of composite oral and maxillofacial defects by free flaps based on a new classification. Sci Rep. $2020 \mathrm{Mar}$ 9;10(1):4300.Pubmed PMID: 32152445.

[23]. Liang J, Yu T, Wang X, Zhao Y, Fang F, Zeng W, et al. Free tissue flaps in head and neck reconstruction: clinical application and analysis of 93 patients of a single institution. Braz J Otorhinolaryngol. 2018 Jul-Aug;84(4):416-425. Pubmed PMID: 28571928.

[24]. Alfouzan AF. Review of surgical resection and reconstruction in head and neck cancer. Traditional versus current concepts. Saudi Med J. 2018 Oct:39(10):971-980.Pubmed PMID: 30284578.

[25]. Chakrabarti S, Chakrabarti PR, Desai SM, Agrawal D, Mehta DY, Pancholi M. Reconstruction in oral malignancy: Factors affecting morbidity of various procedures. Ann Maxillofac Surg. 2015 Jul-Dec;5(2):191-7.Pubmed PMID: 26981469.

[26]. Carlson ER. The use of local flaps to close maxillary defects. J Oral Maxillofac Surg. 2003 Aug 1;61(8):11a.

[27]. Liu WW, Zhang CY, Li JY, Zhang MF, Guo ZM. A novel classification system for the evaluation and reconstruction of oral defects following oncological surgery. Oncol Lett. 2017 Dec;14(6):7049-7054.Pubmed PMID: 29344134.

[28]. Mavrogenis AF, Igoumenou VG, Ignatiadis I, Mourouzis K, Rallis G, Spyridonos SG. Microsurgical reconstruction of complex oromandibular defects: An update. Injury. 2019 Dec;50 Suppl 5:S117-S122.Pubmed PMID: 31732121. 